\title{
Strategies for recovery and regeneration after brain and spinal cord injury
}

\section{H Tator}

See end of article for

author's affiliation

......................

Correspondence to:

$\mathrm{Dr} C \mathrm{H}$ Tator, Professor of

Neurosurgery, Toronto

Western Hospital, Room

4W-433, 399 Bathurst

Street, Toronto, ON

Canada M5T 2S8:

charles.tator@uhn.on.ca

\begin{abstract}
Current knowledge of the epidemiology and pathophysiology of neurotrauma and the key clinical and experimental strategies for promoting recovery and regeneration after brain and spinal cord trauma are reviewed. Brief overviews of the epidemiology and pathophysiology of neurotrauma are presented, and the key experimental and clinical treatments for the promotion of recovery and regeneration after brain and spinal cord trauma are discussed.
\end{abstract}

Injury Prevention 2002;8(Suppl IV):iv33-iv36

$\mathrm{N}$ eurotrauma represents a significant proportion of the trauma burden with respect to incidence, mortality, disability, and costs. There has been a remarkable improvement in our understanding of the pathophysiology of neurotrauma. This knowledge has resulted from the development of several experimental models of brain and spinal cord injury which simulate many of the common mechanisms of human injuries. A large number of secondary injury mechanisms have been elucidated including vascular, cellular, ionic, and metabolic derangements. Many neuroprotective strategies have been successful in preclinical trials, and several have been examined in large clinical trials, including many randomized prospective control clinical trials. Unfortunately, very few agents have been successful in improving function in patients with brain or spinal cord injury. Nimodipine improves neurological function in a specific type of brain injury in humans, and there is some evidence that methylprednisolone improves neurological recovery in human spinal cord injury. However, improved triage and acute resuscitation have improved recovery and reduced mortality. Promising experimental results have been achieved with several new strategies to promote regeneration of irreparably damaged central nervous system tissue, the most exciting of which have involved either transplantation of nervous tissue and administration of neurotrophic factors; some of these are currently being applied to humans. There have also been major improvements in the system of care of neurotrauma victims, including better triage and first aid; and useful clinical care guidelines have been developed and distributed in many countries.

\section{EPIDEMIOLOGY OF NEUROTRAUMA AND THE RELATIVE IMPORTANCE OF NEUROTRAUMA}

In terms of mortality or lifelong disability, brain and spinal cord injury rank highly as important types of trauma. For example, Kraus ${ }^{1}$ found that $57 \%$ of all high acuity trauma patients have some neurologic injury, and that half of the 150000 injury related deaths that occur annually in the US involve a serious brain injury that is primarily responsible for the patient's demise. In Canada, a recent study conducted by the National Trauma Registry ${ }^{2}$ showed that for a 12 month period in 1998-99 there were 21163 head injury admissions and 1347 spinal cord injury admissions. The head injuries represented $11 \%$ of injury admissions; the peak percentage was in 15-34 year olds, and the leading causes were unintentional falls $(44 \%)$ and motor vehicle crashes (32\%). The spinal cord injuries represented $1 \%$ of injury admissions; the leading causes were motor vehicle crashes (43\%) and unintentional falls (36\%). Other frequent causes of neurotrauma in Canada are injuries at work and injuries in sports and recreation. Falls at home, especially among seniors, ${ }^{2}$ are very common causes of neurotrauma. In some countries, violence is also a major cause of neurotrauma, especially gunshot wounds and other penetrating injuries. Each major brain or spinal cord injury costs society several million dollars for medical costs and lost earnings in addition to the great personal loss sustained by the victims and their families.

\section{EXPERIMENTAL MODELS AND THE PATHOPHYSIOLOGY OF NEUROTRAUMA}

The diversity of neurotrauma in humans has required that investigators develop several types of experimental laboratory models of brain or spinal cord injury to simulate the human conditions. The brain injury models have involved acute or chronic compression of the brain to simulate the life threatening compressive lesions such as subdural haematomas, or models which produce concussive and shear forces on the brain to simulate human injuries such as diffuse brain injury and the accompanying tearing of axons. ${ }^{3}$ Similarly, in the spinal cord injury field a variety of models have been developed to simulate the common mechanisms of acute contusive forces and continuing compression. ${ }^{4}$ Knowledge of the pathophysiology of acute neurotrauma has increased dramatically during the past 10 years. There is evidence for both primary and secondary injury mechanisms. The primary injury is due to mechanical factors such as direct contusion or compression, and the secondary injury is due to one or more damaging processes initiated by the primary injury. ${ }^{5-7} \mathrm{CNS}$ tissue undergoes sequential pathological changes after injury including hemorrhage, edema, axonal and neuronal necrosis, and demyelination followed by cyst formation and infarction. The vascular affects of neurotrauma have been extensively studied in experimental models, especially in spinal cord injury. There is strong evidence based on microangiographic and blood flow techniques that severe injury produces major vascular effects consisting of early arterial and venous hemorrhage followed by post-trauma ischaemia due to platelet aggregation and vasospasm. ${ }^{89}$ There are a number of other damaging secondary injury processes affecting neuronal and glial cells including electrolyte shifts such as increased intracellular calcium, 
excitotocity especially due to glutamate, eicosanoid excess, damage due to inflammation, and apoptosis. Widespread axonal injuries have been documented after even mild brain injury, and there is strong evidence that diffuse axonal injury is one of the major pathological effects of severe brain injury. ${ }^{10}$ There is also experimental evidence for the cumulative effect of repeated brain injury. ${ }^{11}$ It appears that there is a genetic factor accounting for the susceptibility to head trauma, the occurrence of repeated trauma, and the risk of the subsequent development of consequences including the possible development of neurodegenerative disorders such as Alzheimer's disease. ${ }^{12}{ }^{13}$ Individuals with the epsilon 4 allele of apolipoprotein E carry an increased risk.

The secondary events begin immediately after trauma, and continue to evolve for days or weeks. Thus, there may be an extended window of opportunity for the application of therapeutic measures.

\section{GUIDELINES, TRIAGE, AND SYSTEMS OF CARE}

The knowledge that deleterious secondary injury processes are set in motion soon after trauma, and that some of these processes are amendable to treatment has lead to intense efforts to improve the organization of care of neurotrauma victims with emphasis on rapid, appropriate triage, rapid first aid, and early institution of restoration of homeostasis. It has become recognized that all first aid personnel must be trained in the ABCs (airway, breathing, and circulation) of brain and spinal cord injury resuscitation, with emphasis on homeostasis including restoration of normotension and normoxia and prevention of hyperthermia and spinal misalignment. Treatment in specialized units especially with the capability for intensive care and invasive monitoring is recommended for the acute phase, and similarly specialized units for the rehabilitation phase. Treatment of the whole patient with insistence on prevention of hypoxia, hypotension, and complications has resulted in a reduction in mortality and improved prospects for recovery. ${ }^{14}$ Neurotrauma specialty organizations have recently published guidelines for best practices utilizing evidence based approaches in brain and cervical spinal injury. ${ }^{15}$ The guidelines are based on the principles of evidence based medicine that include grading and classification of the degree of certainty of clinical and experimental evidence. There has also been a very useful trend in most countries to recommend the adoption and use of standardized, consistent methods for the clinical scoring of the neurological examination and neurological outcome for brain injury, utilizing the Glasgow Coma Scale and Glasgow Outcome Scale ${ }^{16-18}$ and the International Spinal Cord Injury Scale (ISCSCI-92, or ASIA Scale) and scoring system ${ }^{19}$ for spinal cord injury. The use of guidelines and standard systems of neurological classification of injuries and assessment of neurological outcomes is highly recommended, especially in rural or remote settings in developed countries and in developing countries where specialist care and specialized facilities may be lacking. The guidelines emphasize the necessity to prevent complications and to view the patient as a whole, and thus it is very likely that they will contribute to improved care and recovery.

\section{PROSPECTS FOR RECOVERY AND REGENERATION AFTER NEUROTRAUMA}

Based on the accurate methods now in widespread use for recording the clinical neurological assessment and outcome in neurotrauma, a body of data is now available as a baseline for evaluating new measures to improve the neurological results after neurotrauma. In the brain injury field, the National Traumatic Coma Data Bank in the USA serves as a useful reference, ${ }^{2021}$ and in the spinal cord injury field, the published experience of the Spinal Cord Injury Model Systems, with almost 10000 cases admitted between 1973 and $1985^{22}$ serves for comparison with subsequent studies. These databanks show that some recovery does occur by natural recovery processes, which likely involves both spontaneous resolution of acute injury events such as swelling and hemorrhage, and general resuscitative and specific therapeutic measures, such as removal of space occupying lesions, including extradural hematomas, in brain injury, and in-driven bone and disc fragments in spinal cord injury. ${ }^{14}{ }^{23-26}$ Recovery has been inversely proportional to the severity of trauma, with less severe injuries showing a much better prognosis. For example, after complete spinal cord injury, the possibility of the return of locomotor function is only about $1 \%,{ }^{27}$ but in incomplete injuries most patients recover some neurological function. ${ }^{28}$ It is of major interest that there has been a gradual shift in incidence from complete to incomplete spinal cord injuries, attributed to improved prevention measures including earlier and more skillful first aid, triage and retrieval, better resuscitation, and seatbelts. ${ }^{29}$ The same factors account for an improvement in the overall prospects for recovery. The reliability of assessing these epidemiological events has improved greatly because of the widespread use of uniform and reliable clinical assessment tools, as noted above.

\section{RECOVERY STRATEGIES}

In general, the strategies to promote recovery have comprised pharmacological methods of providing neuroprotection and surgical methods to relieve compression by measures such as removal of surface haematomas. Pharmacological strategies have been designed to counteract the specific secondary injury mechanisms such as glutamate excitotoxicity, lipid peroxidation, free radical production, electrolyte shifts, and ischaemia, elucidated in the pathophysiological studies with the experimental models described above; several clinically successful strategies have emerged.

In brain injury, there have been more than 50 clinical trials in the past 20 years, mostly randomized prospective controlled trials. ${ }^{30-32}$ For example, nimodipine, a calcium channel antagonist designed to reduce cerebral vasospasm by reducing intracellular calcium, improves the recovery from brain injury in patients with accompanying traumatic subarachnoid hemorrhage. ${ }^{33}$ Unfortunately, clinical trials to reduce glutamate toxicity with measures such as NMDA receptor blockade have failed, partly due to undesirable side effects. In general, trials with anticonvulsants, barbiturates, hyperventilation, and control of raised intracranial pressure have produced negative or conflicting results. ${ }^{30}$ After several conflicting or inconclusive trials of various corticosteroids in brain injury, a very large trial of corticosteroids is currently underway in 20000 patients with acute brain injury. ${ }^{34}$ There is strong evidence that recovery is related to the control of raised intracranial pressure, and that agents such as mannitol and barbiturates can reduce intracranial pressure. ${ }^{35}$ Although induced hypothermia has not been successful at improving outcome after brain injury, ${ }^{36}$ the studies have emphasized the importance of preventing sepsis and fever. It has been postulated that because of the multitude of secondary injury mechanisms to counteract, successful treatment may require combinations of therapies. ${ }^{31}$

In spinal cord injury, there have been 10 randomized prospective control trials as recently reviewed by Tator and Fehlings. ${ }^{37}$ For example, methylprednisolone was shown to improve clinical neurological recovery in two large trials. ${ }^{38} 39$ However, the improvement in neurological recovery was minimal, and there was an increased rate of sepsis. Indeed, there is continuing controversy about the use of this agent in acute spinal cord injury. ${ }^{40}$ "Aggressive" medical management with invasive monitoring and the use of vasopressors to restore normotension is being pursued in many spinal cord injury centers ${ }^{41}$ and there is some clinical interest in early surgical decompression ${ }^{26}$ based on clinical and laboratory evidence. ${ }^{42}$ However, the only clinical randomized prospective control trial 
of spinal cord decompression showed no significant difference between early and late decompression. ${ }^{43}$ It should be noted that the average time to decompression in the early group was 1.8 days which is much longer than the time windows for effective therapy shown in most experimental trials. ${ }^{44}$ Attempts to alter the inflammatory and immune responses to neurotrauma have been made at both the experimental and clinical levels. ${ }^{45}{ }^{46}$ Functional improvement in the rehabilitation and chronic phases has been shown in incomplete spinal cord injury following pharmacotherapy with 4-aminopyridine, a potassium channel blocker designed to prevent potassium entry into demyelinated axons, ${ }^{47}{ }^{48}$ and with physical means such as gait training with gravity assistance methods. ${ }^{49}$ The latter technique may stimulate both recovery and regenerative processes.

There is a need for further laboratory investigations and clinical trials of neuroprotection for neurotrauma. For example, we now know that apoptosis continues for several weeks after injury, and that there are antiapoptotic agents which can prevent this continuing loss of cells in experimental studies. ${ }^{50}$

\section{REGENERATION STRATEGIES}

Neuroprotection and related strategies such as control of raised intracranial pressure and spinal decompression are more effective with less severe injuries. In contrast, major injuries of the brain or spinal cord require actual regeneration of central nervous system tissue for effective restoration of function. Recent research shows that there is considerable potential for regeneration of adult mammalian brain and spinal cord tissue. One of the most exciting discoveries has been the finding that the adult mammalian central nervous system is capable of regeneration through the presence of stem and progenitor cells in the brain ${ }^{5152}$ and spinal cord. ${ }^{534}$ A large number of regeneration strategies have shown promising results in experimental settings including transplantation, neurotrophic factors, and gene therapy. ${ }^{55}$ Neurotrophic factors produce remarkable proliferation of nervous tissue in vitro and in vivo and have produced improvement of function in several experimental models of neurotrauma. Indeed, specific types of neural and glial regeneration can be induced by specific neurotrophic agents. For example, the neurotrophic factor BDNF produces a dramatic proliferation of Schwann cells, axonal regeneration, and myelination in the injured spinal cord. ${ }^{56}$ Indeed, rehabilitation with methods such as physiotherapy has been placed on a much firmer basis with the discovery that the brain produces increased levels of neurotrophic factors during exercise..$^{57} 5 y$ Systemic or intrathecal neurotrophic factors have not yet been successful in patients with non-traumatic neurological disorders, ${ }^{59}$ although there have been no reported trials in patients with brain or spinal cord injury. Various types of transplant ranging from peripheral nerves ${ }^{60}$ to whole segments of fetal or adult spinal cord $^{6162}$ have been shown to attach to injured CNS tissue and to support axonal regeneration. Indeed, fetal cord tissue has been transplanted into patients with post-traumatic syringomyelia. ${ }^{63}$ Peripheral nerve transplantation strategies are based on the seminal experimental work by Richardson and colleagues ${ }^{64}$; and recently patients with spinal cord injury have shown limited functional improvement after peripheral nerve grafts were inserted into the spinal cord rostral to the injury site, in order to create a bridge from the spinal cord to successfully reinnervate previously non-functioning muscles. ${ }^{65}$

\section{CONCLUSIONS}

In summary, research has provided a great deal of information about primary and secondary responses to neurotrauma that are highly relevant to the management of patients with brain and spinal cord injury. In addition, there are a number of experimental strategies for enhancing recovery through neuroprotection and related strategies, and for enhancing regeneration through means such as transplantation, stem cells, and neurotrophic factors. Some of these strategies have been successfully applied to patients, and there is strong hope that further clinical recovery and regeneration may be possible in humans after brain or spinal cord injury. To date, the improvements in neurological recovery are mainly related to the more widespread application of sound principles of early triage and aggressive resuscitation with strict attention to the prevention of hypotension and hypoxia, and to the early relief of persisting compression of damaged nervous tissue.

\section{Author's affiliation}

C H Tator, University of Toronto and Toronto Western Hospital, Canada

\section{REFERENCES}

1 Kraus J. Epidemiology of head injury. In: Cooper P, ed. Head injury. Baltimore, MD: Williams and Wilkins, 1993:1-25.

2 National Trauma Registry. Injury statistics in Canada, 1998-99. HIA 2001.

3 Povlishock J. An overview of brain injury models. In: Narayan RJW Jr, Povlishock J, eds. Neurotrauma. New York: McGraw-Hill, 1996:1325-36.

4 Fehlings MG, Tator $\mathrm{CH}$. A review of experimental models of acute spinal cord injury. In: Illis, ed. Spinal cord dysfunction: assessment. Oxford: Oxford University Press, 1988:3-43.

5 Tator $\mathrm{CH}$. Pathophysiology and pathology of spinal cord injury. In: Wilkins RH, Rengachary SS, eds. Neurosurgery. New York: McGraw-Hill, 1996:2847-59.

6 Graham DI, Adams JH, Doyle D, et al. Quantification of primary and secondary lesions in severe head injury. Acta Neurochir Suppl (Wien) 1993;57:41-8.

7 Gennarelli TA. Mechanisms of brain injury. J Emerg Med 1993;11 (suppl 1):5-11.

8 Koyanagi I, Tator CH, Lea PJ. Three-dimensional analysis of the vascular system in the rat spinal cord with scanning electron microscopy of vascular corrosion casts. Part 2: Acute spinal cord injury. Neurosurgery 1993;33:285-92.

9 Anthes DL, Theriault E, Tator CH. Ultrastructural evidence for arteriolar vasospasm after spinal cord trauma. Neurosurgery 1996;39:804-14.

10 Povlishock JT. Pathophysiology of neural injury: therapeutic opportunities and challenges. Clin Neurosurg 2000;46:113-26.

11 Laurer HL, Bareyre FM, Lee VM, et al. Mild head injury increasing the brain's vulnerability to a second concussive impact. J Neurosurg 2001;95:859-70.

12 Teasdale GM, Nicoll JA, Murray G, et al. Association of apolipoprotein E polymorphism with outcome after head injury. Lancet 1997;350:1069-71.

13 Graham DI, Horsburgh K, Nicoll JA, et al. Apolipoprotein E and the response of the brain to injury. Acta Neurochir Suppl (Wien) 1999:73:89-92.

14 Chesnut RM, Marshall LF, Klauber MR, et al. The role of secondary brain injury in determining outcome from severe head injury. J Trauma 1993;34:216-22

15 Anon. Guidelines for managament of acute cervical spinal injuries. Neurosurgery 2002;50:S1-199.

16 Jennett B, Teasdale $G$. Aspects of coma after severe head injury. Lancet 1977;1:878-81

17 Jennett B, Snoek J, Bond MR, et al. Disability after severe head injury observations on the use of the Glasgow Outcome Scale. J Neurol Neurosurg Psychiatry 1981;44:285-93.

18 Teasdale G, Jennett B. Assessment of coma and impaired consciousness. A practical scale. Lancet 1974;2:81-4.

19 Association ASI. Standards for neurological and functional classification of spinal cord injury. Revised edition. Chicago: American Spinal Injury Association, 1992.

20 Marshall LF, Toole BM, Bowers SA. The National Traumatic Coma Data Bank. Part 2: Patients who talk and deteriorate: implications for treatment. J Neurosurg 1983;59:285-8.

21 Marshall LF, Becker DP, Bowers SA, et al. The National Traumatic Coma Data Bank. Part 1: Design, purpose, goals, and results. J Neurosurg 1983;59:276-84.

22 Stover SL, DeLisa JA, Whiteneck GG. Spinal cord injury. Clinical outcomes from the model systems. Gaithersburg, MD: Aspen Publications, 1995.

23 Miller JD, Butterworth JF, Gudeman SK, et al. Further experience in the management of severe head injury. J Neurosurg 1981;54:289-99.

24 Seelig JM, Becker DP, Miller JD, et al. Traumatic acute subdural hematoma: major mortality reduction in comatose patients treated within four hours. N Engl J Med 1981;304:1511-18.

25 Marshall L, Gautille T, Klauber M, et al. The outcome of severe closed head injury. J Neurosurg 1991;75:S28-36. 
26 Fehlings $M$ G , Sekhon $\mathrm{LH}$, Tator $\mathrm{C}$. The role and timing of decompression in acute spinal cord injury: what do we know? What should we do? Spine $2001 ; 26(24$ suppl):S101-10.

27 Hansebout R. Comprehensive review of methods of improving cord recovery after acute spinal cord injury. In: Tator $\mathrm{C}$, ed. Early management of acute spinal cord injury. New York: Raven Press, 1982:181-96.

28 Tator $\mathrm{CH}$, Duncan EG, Edmonds VE, et al. Neurological recovery, mortality and length of stay after acute spinal cord injury associated with changes in management. Paraplegia 1995;33:254-62.

29 Tator C. Epidemiology and general characteristics of the spinal cord injury patient. In: Benzel E, Tator $\mathrm{CH}$, eds. Contemporary management of spinal cord injury. Park Ridge, IL: American Association of Neurological Surgeons, 1995:9-13.

30 Garton H, Luerssen T. Head injuries. In: Biller J, Bogousslavsky J, eds. Clinical trials in neurologic practice. Woburrn, $M A$ : Butterworth-Heinemann, 2001:77-98.

31 Clausen T, Bullock R. Medical treatment and neuroprotection in traumatic brain injury. Curr Pharm Des 2001;7:1517-32.

32 Narayan RK, et al. Clinical trials in head injury. J Neurotrauma 2002; 19:503-57.

33 Harders A, Kakarieka A, Braakman R. Traumatic subarachnoid hemorrhage and its treatment with nimodipine. German ISAH Study Group. J Neurosurg 1996;85:82-9.

34 Kmietowicz Z. Trial of steroids for treating head injury begins. BM 1999;318:1441.

35 Schwartz ML, Tator CH, Rowed DW, et al. The University of Toronto head injury treatment study: a prospective, randomized comparison of pentobarbital and mannitol. Can J Neurol Sci 1984;1 1:434-40.

36 Clifton GL, Miller ER, Choi SC, et al. Lack of effect of induction of hypothermia after acute brain injury. N Engl J Med 2001;344:556-63

37 Tator C, Fehlings M. Clinical trials in spinal cord injury. In: Biller J, Bogousslavsky J, eds. Clinical trials in neurologic practice. Blue books of practical neurology. Boston, MA: Butterworth-Heinemann, 2001:99-120.

38 Bracken MB, Shepard M, Collins WF, et al. A randomized, controlled trial of methylprednisolone or naloxone in the treatment of acute spinal-cord injury. Results of the Second National Acute Spinal Cord Injury Study. N Engl J Med 1990;322:1405-1 1

39 Bracken MB, Shepard M, Holford TR, et al. Methylprednisolone or tirilazad mesylate administration after acute spinal cord injury: 1-year follow up. Results of the third National Acute Spinal Cord Injury randomized controlled trial. J Neurosurg 1998;89:699-706.

40 Hurlbert RJ. Methylprednisolone for acute spinal cord injury: an inappropriate standard of care. J Neurosurg 2000;93(1 suppl): 1-7.

41 Vale FL, Burns J, Jackson AB, et al. Combined medical and surgical treatment after acute spinal cord injury: results of a prospective pilot study to assess the merits of aggressive medical resuscitation and blood pressure management. J Neurosurg 1997;87:239-46.

42 Fehlings MG, Tator $\mathrm{CH}$. An evidence-based review of decompressive surgery in acute spinal cord injury: rationale, indications, and timing based on experimental and clinical studies. J Neurosurg 1999;91/1 suppl): $1-11$.

43 Vaccaro AR, Daugherty RJ, Sheehan TP, et al. Neurologic outcome of early versus late surgery for cervical spinal cord injury. Spine 1997:22:2609-13.

44 Tator $\mathbf{C H}$. Biology of neurological recovery and functional restoration after spinal cord injury. Neurosurgery 1998;42:696-708.
45 Schwartz M, Lazarov-Spiegler O, Rapalino O, et al. Potential repair of rat spinal cord injuries using stimulated homologous macrophages. Neurosurgery 1999;44:1041-6.

46 David S, Ousman SS. Recruiting the immune response to promote axon regeneration in the injured spinal cord. Neuroscientist 2002;8:33-41.

47 Potter PJ, et al. Randomized double-blind crossover trial of fampridine-SR (sustained release 4-aminopyridine) in patients with incomplete spinal cord injury. J Neurotrauma 1998;15:837-49.

48 Darlington C. Fampridine Acorda Therapeutics. Curr Opin Investig Drugs 2000; 1:375-9.

49 Dietz V. Spinal cord lesion: effects of and perspectives for treatment Neural Plast 2001;8:83-90.

50 Casha S, Yu WR, Fehlings MG. Oligodendroglial apoptosis occurs along degenerating axons and is associated with FAS and p75 expression following spinal cord injury in the rat. Neuroscience 2001;103:203-18.

51 McKay R. Stem cells in the central nervous system. Science 1997;276:66-71.

52 Morshead CM, Reynolds BA, Craig CG, et al. Neural stem cells in the adult mammalian forebrain: a relatively quiescent subpopulation of subependymal cells. Neuron 1994;13:1071-82

53 Weiss S, Dunne C, Hewson J, et al. Multipotent CNS stem cells are present in the adult mammalian spinal cord and ventricular neuroaxis. $J$ Neurosci 1996;16:7599-609.

54 Namiki J, Tator $\mathrm{CH}$. Cell proliferation and nestin expression in the ependyma of the adult rat spinal cord after injury. J Neuropathol Exp Neurol 1999;58:489-98.

55 Schwab ME, Bartholdi D. Degeneration and regeneration of axons in the lesioned spinal cord. Physiol Rev 1996;76:319-70.

56 Namiki J, Kojima A, Tator $\mathrm{CH}$. Effect of brain-derived neurotrophic factor, nerve growth factor, and neurotrophin-3 on functional recovery and regeneration after spinal cord injury in adult rats. J Neurotrauma 2000;17:1219-31

57 Neeper SA, Gomez-Pinilla F, Choi J, et al. Exercise and brain neurotrophins. Nature 1995; 373:109.

58 Cotman CW, Berchtold NC. Exercise: a behavioral intervention to enhance brain health and plasticity. Trends Neurosci 2002;25:295301

59 Penn RD, Kroin JS, York MM, et al. Intrathecal ciliary neurotrophic factor delivery for treatment of amyotrophic lateral sclerosis (phase I trial). Neurosurgery 1997;40:94-100

60 Cheng H, Cao Y, Ólson L. Spinal cord repair in adult paraplegic rats: partial restoration of hind limb function. Science 1996;273:510-13.

61 Bregman BS, Kunkel-Bagden E, Reier PJ, et al. Recovery of function after spinal cord injury: mechanisms underlying transplant-mediated recovery of function differ after spinal cord injury in newborn and adult rats. Exp Neurol 1993; 123:3-16

62 Reier PJ, Anderson DK, Thompson FJ, et al. Neural tissue transplantation and CNS trauma: anatomical and functional repair of the injured spinal cord. J Neurotrauma 1992:9(suppl 1):S223-48.

63 Wirth ED III, Reier PJ, Fessler RG, et al. Feasibility and safety of neural tissue transplantation in patients with syringomyelia. J Neurotrauma 2001;18:911-29.

64 Richardson PM, McGuinness UM, Aguayo AJ. Axons from CNS neurons regenerate into PNS grafts. Nature 1980;284:264-5.

65 Brunelli GA. Direct neurotization of muscles by presynaptic motoneurons. J Reconstr Microsurg 2001;17:631-6. 